University of Nebraska - Lincoln

DigitalCommons@University of Nebraska - Lincoln

January 2001

\title{
Aluminum doping of poly(vinylidene fluoride with trifluoroethylene) copolymer
}

B. $\mathrm{Xu}$

University of Nebraska-Lincoln

C.N. Borca

University of Nebraska - Lincol

Stephen Ducharme

University of Nebraska, sducharme1@unl.edu

A.V. Sorokin

University of Nebraska-Lincoln

Peter A. Dowben

University of Nebraska-Lincoln, pdowben@unl.edu

See next page for additional authors

Follow this and additional works at: https://digitalcommons.unl.edu/physicsdowben

Part of the Physics Commons

Xu, B.; Borca, C.N.; Ducharme, Stephen; Sorokin, A.V.; Dowben, Peter A.; Fridkin, V.M.; Palto, S.P.; Petukhova, N.N.; and Yudin, S.G., "Aluminum doping of poly(vinylidene fluoride with trifluoroethylene) copolymer" (2001). Peter Dowben Publications. 167.

https://digitalcommons.unl.edu/physicsdowben/167

This Article is brought to you for free and open access by the Research Papers in Physics and Astronomy at DigitalCommons@University of Nebraska - Lincoln. It has been accepted for inclusion in Peter Dowben Publications by an authorized administrator of DigitalCommons@University of Nebraska - Lincoln. 


\section{Authors}

B. Xu, C.N. Borca, Stephen Ducharme, A.V. Sorokin, Peter A. Dowben, V.M. Fridkin, S.P. Palto, N.N. Petukhova, and S.G. Yudin 


\title{
Aluminum doping of poly(vinylidene fluoride with trifluoroethylene) copolymer
}

\author{
B. Xu, C. N. Borca, S. Ducharme, A. V. Sorokin, ${ }^{\text {a) }}$ and P. A. Dowben ${ }^{\text {b) }}$ \\ Department of Physics and Astronomy and the Center for Materials Research and Analysis, \\ Behlen Laboratory of Physics, University of Nebraska-Lincoln, Lincoln, Nebraska 68588-0111
}

V. M. Fridkin, S. P. Palto, N. N. Petukhova, and S. G. Yudin

The Russian Academy of Sciences, 59 Leninsky Prospekt, 117333 Moscow, Russia

(Received 28 August 2000; accepted 27 October 2000)

\begin{abstract}
The interface between aluminum and crystalline copolymer thin film of vinylidene fluoride $(70 \%)$ with trifluoroethylene (30\%) [PVDF-TrFE] has been studied. The ratio of carbon $1 s$ and aluminum $2 p$ core level photoemission peak intensities changes little with increasing emission angle after deposition of $5 \AA$ aluminum on the surface of PVDF-TrFE. This indicates that the distribution of aluminum atoms in the copolymer film is quite uniform in the near surface region and the interface between PVDF-TrFE and aluminum is not abrupt. There is evidence for changes in photohole screening with aluminum doping within the polymer film. (C) 2001 American Institute of Physics. [DOI: 10.1063/1.1334351]
\end{abstract}

There exist a large number of studies of aluminum doping of large organic molecular overlayers. The aluminum atoms were found to interact with the conjugated systems ( $\alpha, \omega$-diphenyltetrahecaheptaene, ${ }^{1}$ alkyl-substituted poly-3octylthiophene, and $\alpha$-sexithiophene oligomer ${ }^{2}$ ) to form covalent bonds, and an aluminum overlayer was believed to form with $\mathrm{Al}$ evaporation with these polymers. Strong interactions were also observed in polyimides and polyesters, ${ }^{3,4}$ but overlayer $\mathrm{Al}$ formation was, nonetheless, observed. Such an observation is a marked contrast to the evaporation of alkali metals on many organic polymers. ${ }^{1,5-7}$ The appearance of states in the region near the chemical potential, between the highest occupied state and lowest unoccupied state (the HOMO-LUMO gap), has been reported for alkali doping of poly(para-phenylenevinylene) ${ }^{6} \quad \alpha, \omega$-diphyltetrahecaheptaene, ${ }^{1,7}$ poly(pyridine-2,5-diyl) ${ }^{8}$ poly $\left(2,2^{\prime}\right.$-bipyridine-5, $5^{\prime}$ -diyl), ${ }^{8}$ and the copolymer vinylidene fluoride $(70 \%)$ with trifluoroethylene $(30 \%){ }^{9}$ These alkali-induced states have been variously ascribed to the formation of lower Hubbard bands, ${ }^{9}$ bipolaron states, ${ }^{6,8}$ and a soliton-antisoliton pair, ${ }^{1,7}$ and the alkali metals generally act and are perceived as doping agents, inducing new states in the otherwise forbidden band gap.

This difference between the alkali metals and aluminum is somewhat key, because aluminum, along with some other metals (typically gold), is generally considered the electrode material(s) of choice for molecular electronics. In this regard, the interface between the metal electrode and the polymer is a key issue in device performance. ${ }^{10}$ In this paper we precisely explore this issue with respect to the interface between aluminum and crystalline copolymer thin films of vinylidene fluoride $(70 \%)$ with trifluoroethylene (30\%) [PVDF-TrFE], a

\footnotetext{
a) Present address: Department of Physics, Ivanovo State University, 153025 Ivanovo, Russia.

${ }^{b)}$ Author to whom correspondence should be addressed.
}

material with recognized excellent dielectric and ferroelectric properties. ${ }^{11,12}$ Angle resolved $\mathrm{x}$-ray photoemission spectroscopy (ARXPS) was used to probe the photoemission screening effects at the surface (compared to the bulk), as well as indicate the chemical state of the metal atoms and provide a measure of whether the metal atoms form clusters or/and diffuse into the thin film.

The crystalline films were formed by LangmuirBlodgett monolayer deposition from a water subphase. ${ }^{13,14}$ The PVDF-TrFE films were deposited on silicon for ARXPS studies. Three types of films were investigated and compared: the clean (undoped) and annealed PVDF-TrFE copolymer crystalline films, the films following $\mathrm{Al}$ deposition, and the films following $\mathrm{Al}$ deposition and annealing. Aluminum was deposited by physical vapor deposition onto the PVDF-TrFE film. The deposition rate was $3 \AA / \mathrm{min}$. The aluminum coverage was determined using a quartz crystal thin film monitor. The annealing temperature after deposition/ doping was $393 \mathrm{~K}$.

Angle-resolved x-ray photoemission spectroscopy (ARXPS) of the $\mathrm{C} 1 s, \mathrm{~F} 1 s$, and $\mathrm{Al} 2 p$ core levels were undertaken with the $\operatorname{Mg} K_{\alpha}$ line $(1253.6 \mathrm{eV})$ on a number of different samples. Energy distribution curves of the elemental $\mathrm{Al} 2 p, \mathrm{C} 1 s$, and $\mathrm{F} 1 s$ core levels were acquired with a large hemispherical electron energy analyzer (PHI Model 10360 Precision Energy Analyzer). The photoemission intensities and core level binding energies were measured as a function of emission angle with respect to the surface normal. ARXPS was performed in a UHV chamber described in detail elsewhere ${ }^{15}$ with a base pressure better than $1 \times 10^{-10}$ Torr.

In Fig. 1 we present a series of ARXPS C $1 s$ spectra of a 5 monolayer (ML) film of clean native P(VDF-TrFE 70:30) (70\% vinylidene with 30\% trifluoroethylene) [Fig. 1(a)], from an aluminum doped sample (with $6 \mathrm{~h}$ annealing) [Fig. 1(b)] as well as $\mathrm{Al} 2 p$ spectra from the sample immediately 


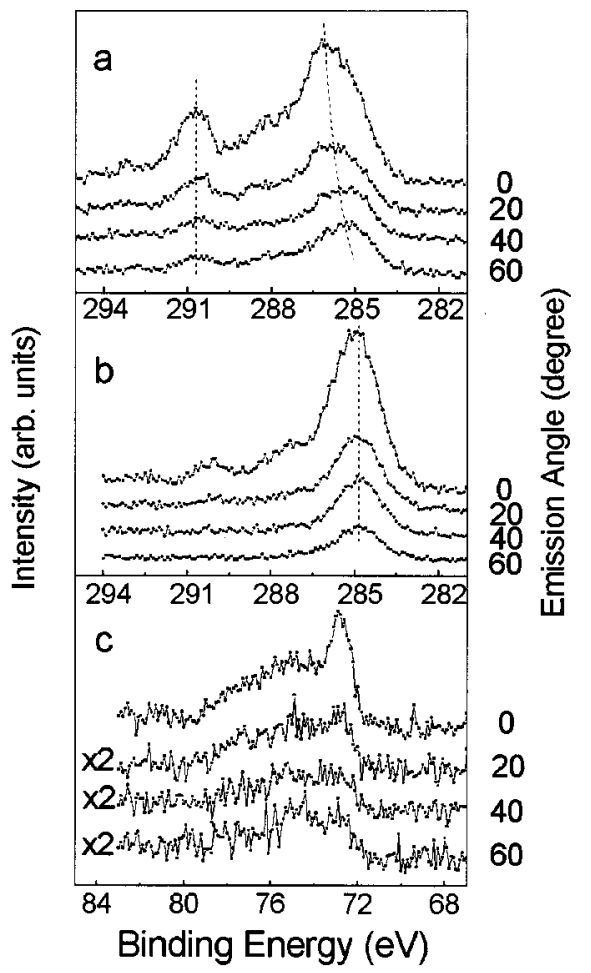

FIG. 1. Angle-resolved x-ray photoemission spectra for a 5 ML crystalline PVDF-TrFE copolymer thin film. The $\mathrm{C} 1 s$ core level from clean PVDFTrFE as a function of emission angle (a), the angle resolved $\mathrm{C} 1 s$ core level at several different emission angles following aluminum deposition and $6 \mathrm{~h}$

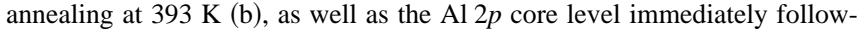
ing deposition on PVDF-TrFE at room temperature (c) are shown.

following aluminum deposition [Fig. 1(c)]. For the clean copolymer sample, the intensity and position of the higher binding energy $(290.7 \pm 0.1 \mathrm{eV}) \mathrm{C} 1 s$ XPS peak is independent of emission angle, while the $\mathrm{C} 1 s$ peak at lower binding energy shifts with increasing emission angles from 285.9 $\pm 0.1 \mathrm{eV}$ at $0^{\circ}$ emission angle to less than $285.1 \pm 0.2$ at $60^{\circ}$ emission angle, as seen in Fig. 1(a). There is also a weak feature at about $288.4 \mathrm{eV}$ binding energy. The fluorine $1 \mathrm{~s}$ core level exhibits a binding energy of $688.3 \pm 0.2 \mathrm{eV}$ from clean copolymer PVDF-TrFE films, as shown in Fig. 2.

The fluorine $1 s$ core level binding energy is $689.6 \mathrm{eV}$ and the $\mathrm{C} 1 s$ binding energies are $286.3 \mathrm{eV}\left(\mathrm{CH}_{2}\right)$ and $290.8 \mathrm{eV}\left(\mathrm{CF}_{2}\right)$ for poly- $\left[\mathrm{CF}_{2}-\mathrm{CH}_{2}-\right]$-, while for poly[- $\left.\mathrm{CF}_{2}-\mathrm{CFH}-\right]$ - the expected $\mathrm{F} 1 s$ binding energy is $690.1 \mathrm{eV}$ and the $\mathrm{C} 1 s$ binding energies are $289.3 \mathrm{eV}(\mathrm{CFH})$ and 291.6 $\mathrm{eV}\left(\mathrm{CF}_{2}\right){ }^{16}$ These reported binding energies (for polymers with no evidence of crystallinity and an indeterminate local bonding geometry) are all far larger than those observed here for crystalline PVDF-TrFE. The differences in core level binding energies can be understood to be a consequence of final state screening effects.

Conduction band spectroscopy ${ }^{9,17,18}$ provides strong evidence that the density of states near $E_{F}$, in the surface region, is greater than in the bulk near room temperature. We can reasonably anticipate that screening of a core photohole at the surface would be better at the surface than in the bulk. The surface has a higher density of states near $E_{F}$ and there-

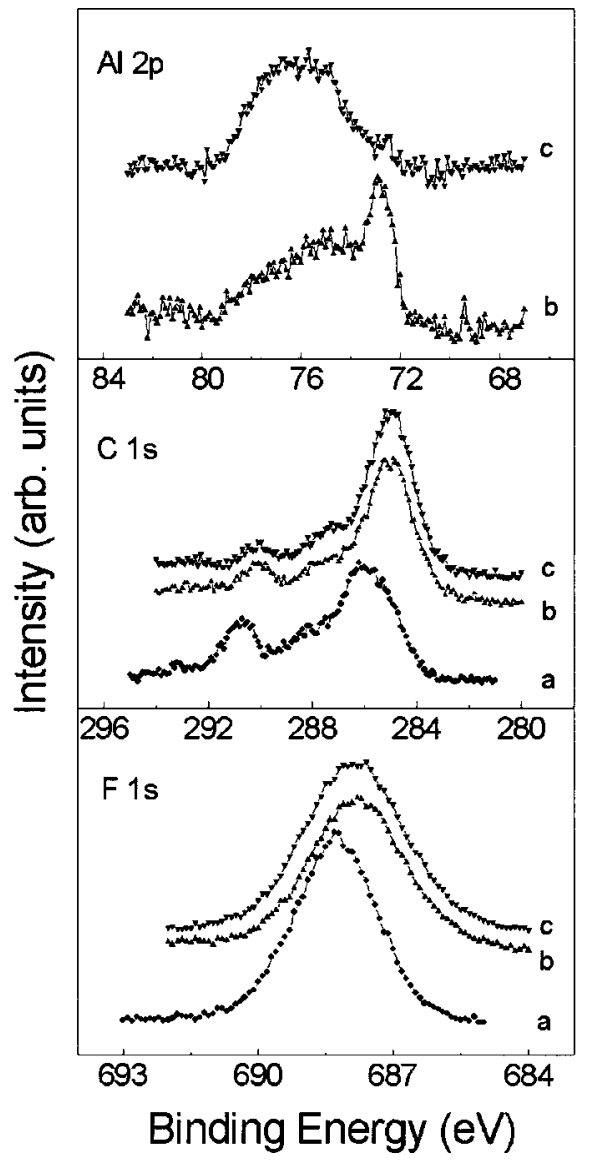

FIG. 2. The $\mathrm{Al} 2 p, \mathrm{C} 1 s$, and $\mathrm{F} 1 s$ x-ray photoemission spectra of the $5 \mathrm{ML}$ crystalline PVDF-TrFE copolymer thin film. The data for the clean PVDFTrFE copolymer film (-) are shown as spectra a in the appropriate panels. The spectra (denoted $b$ in each panel) following aluminum deposition on the film without annealing ( $\mathbf{\Lambda})$ and the spectra (denoted $\mathrm{c}$ in each panel) following aluminum deposition of the film followed with $6 \mathrm{~h}$ annealing at 393 $\mathrm{K}(\boldsymbol{\nabla})$ are shown together. Emission is normal to the surface.

fore provides a larger (Thomas-Fermi) screening parameter (the reciprocal of the screening length) at the surface. The latter Thomas-Fermi screening would favor the more screened final state. This should lead to a smaller binding energy (the electron well screened from the photohole leaves with greater kinetic energy) from a photoemission event at the surface. Increasing the emission angle increases the surface sensitivity of core level photoemission (as noted below). The relative intensity of the higher binding energy $\mathrm{C} 1 s$ core level $\left(\mathrm{CF}_{2}\right)$ decreases significantly [Fig 1(a)]. Since it has already been established that $-\mathrm{CH}_{2}$ - sits high on the surface (toward the vacuum), ${ }^{16}$ we can attribute the core level shift of the $\mathrm{C} 1 s$ binding energy for $\mathrm{CH}_{2}$ (the lower binding energy $\mathrm{C} 1 s$ core level) to surface screening. The higher binding energy $\mathrm{C} 1 s$ core level may be due to the $\mathrm{CF}_{2}$, as previously assigned, ${ }^{15}$ though more likely (on the basis of the data presented here) this higher lying $\mathrm{C} 1 s$ core is due to an unscreened final state (in the just described scheme) and not sensitive to the higher surface density of states (and concomitant screening) because the surface carbon in $\mathrm{CF}_{2}$, as well as the carbon atoms in the "bulk" polymer sits below the plane of the surface. ${ }^{16}$ More precise assignment of chemical state to the core level binding energies requires a 
clear distinction between initial and final states in photoemission (which may not be possible in polymers) and was not undertaken in previous core level photoemission studies. ${ }^{16} \mathrm{In}$ any case, screening of the photohole and final state shifts in the core level photoemission are strong effects in this system.

After aluminum deposition or doping, all the core level photoemission peaks have binding energies independent of emission angles, as seen in Fig. 1(b), but shift again to smaller binding energies with respect to the clean native PVDF-TrFE film.

The nominal $5 \AA$ thick aluminum film (as determined from the thin film thickness monitor) was deposited on $5 \mathrm{ML}$ thick copolymer P(VDF-TrFE 70:30) film at room temperature. The aluminum XPS core level spectrum from a fresh aluminum deposition exhibits an $\mathrm{Al} 2 p$ line shape with two distinct features: a sharp peak located at $72.8 \mathrm{eV}$ suggests the formation of metallic clusters ${ }^{19}$ and a broad peak at a higher binding energy $(\sim 76 \mathrm{eV})$, as seen in Fig. 2. Distribution of the $\mathrm{Al}$ atoms in the copolymer film becomes quite uniform with increasing annealing time: The metallic contribution disappears and the broad peak becomes sharper. The binding energy for the $\mathrm{Al} 2 p$ after annealing, at $76.1 \pm 0.3 \mathrm{eV}$ is quite different from that of bulk metal $\left(72.5 \mathrm{eV}\right.$ for $2 p_{3 / 2}$ and 72.9 $\mathrm{eV}$ for $2 p_{1 / 2}$ ) suggests a lower electron density comparing to metallic aluminum and charge transfer to the PVDF-TrFE copolymer may contribute to this shift. The binding energy of $\mathrm{Al} 2 p$ is close to that found in the literature for $\mathrm{AlF}_{3} .{ }^{19}$

The XPS C $1 s$ and F $1 s$ line shapes of the copolymer film change as the aluminum atoms are deposited at room temperature. As we can see in Fig. 2, all peaks shift about $1 \mathrm{eV}$ to the lower binding energy right after aluminum doping. Since all the core levels attributable to the polymer (both $\mathrm{C} 1 s$ and $\mathrm{F} 1 s$ cores) shift to lower binding energies, we conclude that the aluminum is not locally bonded to the fluorine or a specific site. Rather, the contribution of the aluminum to the PVDF-TrFE is delocalized with respect to a specific carbon or fluorine site. This is quite different from $\mathrm{Na}$ doping, ${ }^{9,20}$ where the Na strongly interacts with the fluorine and the core level shifts are most pronounced for the F $1 s$ core. ${ }^{20}$ Since the core level shifts of the $\mathrm{C} 1 s$ and $\mathrm{F} 1 s$ cores persist after annealing, these $\mathrm{C} 1 s$ and $\mathrm{F} 1 s$ core levels shift with aluminum doping, providing further support to our contention that screening is a dominant effect on the binding energy, even though the $\mathrm{Al} 2 p$ core level signature of "metallic" is gone and there is no appreciable $\mathrm{Al}$ valence band density of states near $E_{F}$. Adding metal atoms (and therefore screening electrons) decreases the binding energy further, as expected in such a picture. Annealing the films, after aluminum deposition, alters the $\mathrm{C} 1 s$ and $\mathrm{F} 1 s$ spectra little. Another important change is the ratio of the intensity of $\mathrm{C} 1 \mathrm{~s}$ peak located at $290.7 \mathrm{eV}$ to that located at $285.9 \mathrm{eV}$ (at normal emission) decreases after aluminum doping. This change, together with the larger binding energy of $\mathrm{Al} 2 p$ in the film, and the evolution of C $1 s$ ARXPS data, indicates a significant preferential bonding or screening of aluminum atoms with these $\mathrm{CF}_{2}$ or unscreened copolymer backbone sites. Nonetheless, there is no $\mathrm{C} 1 s$ core level feature indicative of a new carbon species appearing with $\mathrm{Al}$ deposition,

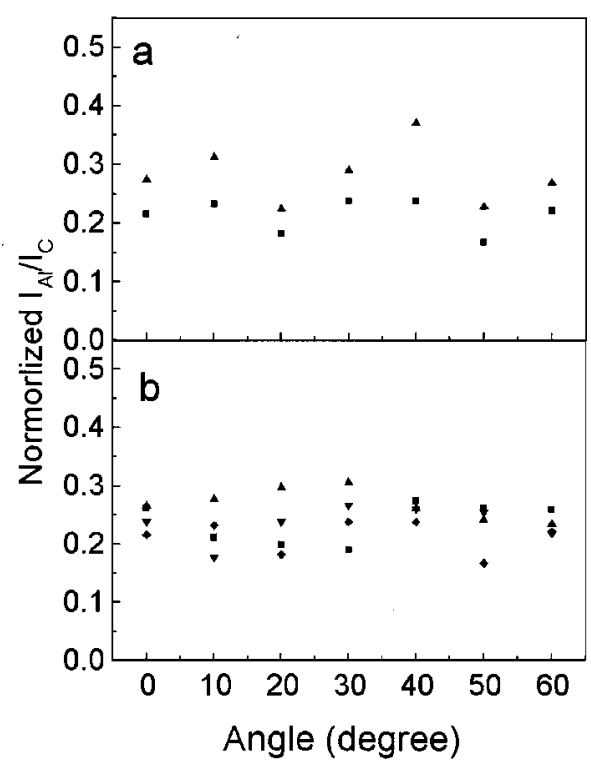

FIG. 3. The angle-resolved $\mathrm{x}$-ray photoemission intensity ratios for the $\mathrm{C} 1 \mathrm{~s}$ and $\mathrm{Al} 2 p$ core levels. The data, in panel a, are from film immediately following $5 \mathrm{ML}$ aluminum deposition at room temperature. The data are compiled from spectra taken as a function of emission angle. The results are plotted excluding the metallic Al peak ( $\square$ ) and including the metallic Al peak $(\boldsymbol{\Delta})$ are shown, with the ratio slightly higher when the entire Al $2 p$ core level contribution is included. For the PVDF-TrFE film following aluminum deposition, the intensity ratios are shown, in panel $b$, comparing different annealing times: before annealing $(\diamond), 1 \mathrm{~h}$ annealing at $393 \mathrm{~K}(\boldsymbol{\nabla}), 6 \mathrm{~h}$ annealing at $393 \mathrm{~K}(\mathbf{\square})$, and $16 \mathrm{~h}$ annealing at $393 \mathrm{~K}(\mathbf{\Delta})$.

which is quite different from what was observed in alkylsubstituted poly-3-octylthiophene (P3OT). ${ }^{2}$ The screening effect of aluminum doping is not localized just to the surface, but extends to the near surface region probed by XPS.

After the different surface preparation procedures, we have plotted the emission angle dependent XPS core level intensity ratios in Fig. 3. The measured XPS intensities $I(\theta)$ for different elemental core levels ( $1 s$ for carbon and $2 p$ for aluminum) are normalized by the corresponding cross sections and transmission factors. The normalized intensity ratio is then given by:

$$
R(\theta)=\left[\frac{I_{A}(\theta) / \sigma_{A}}{I_{B}(\theta) / \sigma_{B}}\right]\left[\frac{E_{\mathrm{kin}}^{p}(A)-C}{E_{\mathrm{kin}}^{p}(B)-C}\right],
$$

where $\theta$ is the emission angle with respect to the surface normal, $\sigma_{A}, \sigma_{B}$ are the cross sections for aluminum and carbon [using the calculations by Scofield for an excitation energy of $\left.1253.6 \mathrm{eV}\left(\operatorname{Mg} K_{\alpha}\right)^{21}\right]$, and the term $E_{\text {kin }}^{p}(A, B)-C$ corrects for the transition of the electron energy analyzer at the kinetic energy of the core level $A$ or $B\left[E_{\text {kin }}^{p}(\mathrm{Al} 2 p)\right.$ $=1179 \mathrm{eV}$ and $\left.E_{\mathrm{kin}}^{p}(\mathrm{C} 1 s)=969 \mathrm{eV}\right]$. Based on the measured transmission functions for this type of analyzer, ${ }^{22}$ we have set $p=0.5, C=0$.

In Fig. 3(a), the emission angle dependent ratio $\left(I_{\mathrm{Al} 2 p} / I_{\mathrm{C} 1 s}\right)$ is plotted, following the fresh deposition of aluminum on the copolymer thin film. These emission angle plots of the intensity ratio have been undertaken including the core level intensity from metallic $\mathrm{Al}$ contribution $(\mathbf{\Delta})$, and excluding (ם) this contribution. Both ratios are almost constant in emission angle. The intensities indicate that fol- 
lowing $\mathrm{Al}$ deposition, at room temperature, the aluminum is uniformly distributed along with the Al clusters, formed immediately after deposition, that are also distributed throughout the near surface region.

Annealing the film after aluminum deposition at $393 \mathrm{~K}$ for different times does little to alter the aluminum distribution. In Fig. 3(b) the ratios, as a function of emission angle, are shown following different annealing times. The results are again constant with increasing emission angle and the ratios are little altered. If the aluminum migrates into the polymer film through simple diffusion, the concentration in the surface region should be dominant by Fick's law. The intensity ratio will be given by:

$$
R(\theta)=\frac{\sum_{j=0}^{\infty} f_{j}(A) e^{-j d /\left\{\lambda_{A} \cos (\theta)\right\}}}{\sum_{j=0}^{\infty} f_{j}(B) e^{-j d /\left\{\lambda_{B} \cos (\theta)\right\}}},
$$

where $\lambda_{\mathrm{Al}}(15 \AA$ for $\mathrm{Al} 2 p), \lambda_{\mathrm{C}}(13 \AA$ for $\mathrm{C} 1 s)$ are the effective mean free paths, ${ }^{23} f_{j}(\mathrm{Al}), f_{j}(\mathrm{C})$ are the exponential profiles for components $\mathrm{Al}$ and $\mathrm{C}$ (or $\mathrm{F}$ ). This ratio, $R(\theta)$, will be constant only if the $\mathrm{Al}$ atoms are uniformly distributed in the near surface region (i.e., for about 5 to $10 \AA$ ).

In conclusion, the diffusion of aluminum atoms into the near surface region of the $5 \mathrm{ML}$ copolymer thin film of PVDF-TrFE is quite rapid even at room temperature. The distribution of aluminum atoms in the $5 \mathrm{ML}$ copolymer thin film is quite uniform as determined from the ARXPS spectra. Aluminum atoms prefer to interact with a more delocalized influence toward the copolymer including both carbon and fluorine. Aluminum provides some core-hole screening of both carbon and fluorine even when apparently well dispersed and without the existence of metallic aluminum clusters. Such doping may induce dramatic changes into the electronic structure and transport properties. This will also be helpful to understand the influence of a free electron gas on the two-dimensional ferroelectric phase transition. ${ }^{11,12}$ The diffusion of aluminum in the near surface or interface region does not appear to extend as significantly into the bulk, as thicker films of PVDF-TrFE retain their excellent dielectric properties even with aluminum contacts. ${ }^{11,12}$

\section{ACKNOWLEDGMENTS}

This work was supported by the ONR, the NSF, and AFOSR Contract No. F30602-98-C-0105 to the W. M. Keck
Center for Molecular Electronics, Subcontract No. 3531141. Palto and Fridkin were supported by the Russian Foundation for Research (\#99-02-16484) and the Inco-Copernicus Program (\#IC15-CT96-0744).

${ }^{1}$ P. Dannetun, M. Lögdlund, C. Fredriksson, R. Lazzaroni, C. Fauquet, S. Stafström, C. W. Spangler, and J. L. Bredas, J. Chem. Phys. 100, 6765 (1994).

${ }^{2}$ P. Dannetun, M. Boman, S. Stafström, W. R. Saleneck, R. Lazzaroni, C. Fredriksson, J. L. Brédas, R. Zamboni, and C. Taliani, J. Chem. Phys. 99, 664 (1993).

${ }^{3}$ P. S. Ho, P. O. Hahn, J. W. Bartha, G. W. Rubloff, F. K. LeGoues, and B. D. Silverman, J. Vac. Sci. Technol. A 3, 739 (1985)

${ }^{4}$ M. Bou, J. M. Martin, T. Le Mogne, and L. Vovelle, in Metallized Plastics 2, edited by K. L. Mittal (Plenum, New York, 1991), p. 219.

${ }^{5}$ M. Lögdlund, R. Lazzaroni, S. Stafström, W. R. Salaneck, and J. L. Brédas, Phys. Rev. Lett. 63, 1841 (1989).

${ }^{6}$ M. Fahlman, D. Beljonne, M. Lögdlund, R. H. Friend, A. B. Holmes, J. L. Brédas, and W. R. Salaneck, Chem. Phys. Lett. 214, 327 (1993).

${ }^{7}$ M. Lögdlund, P. Dannetun, S. Stafström, W. R. Salaneck, M. G. Ramsey, C. W. Spangler, C. Fredricksson, and J. L. Brédas, Phys. Rev. Lett. 70, 970 (1993).

${ }^{8}$ T. Miyamae, D. Yoshimura, H. Ishii, Y. Ouchi, T. Miyazaki, T. Koike, T. Yamamoto, and K. Seki, J. Electron Spectrosc. Relat. Phenom. 78, 399 (1996)

${ }^{9}$ J. Choi, P. A. Dowben, C. N. Borca, S. Adenwalla, A. V. Bune, S. Ducharme, V. M. Fridkin, S. P. Palto, and N. Petukhova, Phys. Rev. B 59, 1819 (1999).

${ }^{10}$ M. Di Ventra, S. T. Pantelides, and N. D. Lang, Phys. Rev. Lett. 84, 979 (2000).

${ }^{11}$ L. M. Blinov, V. M. Fridkin, S. P. Palto, A. V. Bune, P. A. Dowben, and S. Ducharme, Usp. Fiz. Nauk 43, 243 (2000).

${ }^{12}$ A. V. Bune, V. M. Fridkin, S. Ducharme, I. M. Blinov, S. P. Palto, A. Sorokin, S. G. Yudin, and A. Zlatkin, Nature (London) 391, 874 (1998).

${ }^{13}$ S. Palto, L. Blinov, A. Bune, E. Dubovik, V. M. Fridkin, N. Petukhova, K. Verhhovskaya, and S. Yudin, Ferroelectric Lett. Sect. 19, 65 (1995).

${ }^{14}$ L. M. Blinov, Sov. Phys. Usp. 31, 623 (1988).

${ }^{15}$ D. N. McIlroy, C. Waldfried, J. Zhang, J.-W. Choi, F. Foong, S.-H. Liou, and P. A. Dowben, Phys. Rev. B 54, 17438 (1996).

${ }^{16}$ D. T. Clark, W. J. Feast, D. Kilcast, and W. K. R. Musgrave, J. Polym. Sci., Polym. Chem. Ed. 11, 389 (1973).

${ }^{17}$ J. Choi, P. A. Dowben, S. Ducharme, V. M. Fridkin, S. P. Palto, N. Petukhova, and S. G. Yudin, Phys. Lett. A 249, 505 (1998).

${ }^{18}$ J. Choi, C. N. Borca, P. A. Dowben, A. Bune, M. Poulsen, S. Pebley, S. Adenwalla, S. Ducharme, L. Robertson, V. M. Fridkin, S. P. Palto, N. Petukhova, and S. G. Yudin, Phys. Rev. B 61, 5760 (2000).

${ }^{19}$ G. E. McGuire, G. K. K. Schweitzer, and T. A. Carlson, Inorg. Chem. 12, 2451 (1973)

${ }^{20}$ B. Xu, J. Choi, C. N. Borca, A. V. Sorokin, P. A. Dowben, S. P. Palto, N. Petukhova, and S. G. Yudin, Appl. Phy. Lett. (in press).

${ }^{21}$ J. H. Scofield, J. Electron Spectrosc. Relat. Phenom. 8, 129 (1976).

${ }^{22}$ M. P. Seah, M. E. Jones, and M. T. Anthony, Surf. Interface Anal. 6, 242 (1984); M. P. Seah, ibid. 20, 243 (1993).

${ }^{23}$ D. R. Penn, J. Electron Spectrosc. Relat. Phenom. 9, 29 (1976). 